\title{
Observations of an auroral streamer in a double oval configuration
}

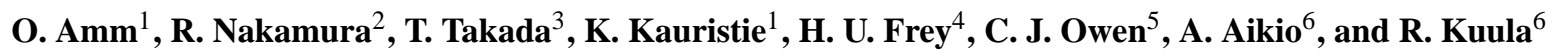 \\ ${ }^{1}$ Finnish Meteorological Institute, Arctic research unit, P.O. Box 503, 00101 Helsinki, Finland \\ ${ }^{2}$ Space Research Institute, Austrian Academy of Sciences, Graz, Austria \\ ${ }^{3}$ Kochi National College of Technology, Nankoku, Japan \\ ${ }^{4}$ Space Sciences Laboratory, University of California, Berkeley, USA \\ ${ }^{5}$ Mullard Space Science Laboratory, Dorking, UK \\ ${ }^{6}$ University of Oulu, Oulu, Finland
}

Received: 4 February 2011 - Revised: 29 March 2011 - Accepted: 30 March 2011 - Published: 27 April 2011

\begin{abstract}
During the late evening and night of 14 September 2004, the nightside auroral oval shows a distinct double oval configuration for several hours after a substorm onset at $\sim 18: 45$ UT. This structure is observed both by the IMAGE satellite optical instruments focusing on the Southern Hemisphere, and by the MIRACLE ground-based instrument network in Scandinavia. At $\sim 21: 17$ UT during the recovery phase of the substorm, an auroral streamer is detected by these instruments and the EISCAT radar, while simultaneously the Cluster satellites observe a bursty bulk flow in the conjugate portion of the plasma sheet in the magnetotail. Our combined data analysis reveals significant differences between the ionospheric equivalent current signature of this streamer within a double oval configuration, as compared to previously studied streamer events without such a configuration. We attribute these differences to the presence of an additional poleward polarization electric field between the poleward and the equatorward portions of the double oval, and show with a simple model that such an assumption can conceptually explain the observations. Further, we estimate the total current transferred in meridional direction by this recovery phase streamer to $\sim 80 \mathrm{kA}$, significantly less than for previously analysed expansion phase streamer events. Both results indicate that the development of auroral streamers is dependent on the ambient background conditions in the magnetosphere-ionosphere system. The auroral streamer event studied was simultaneously observed in the conjugate Northern and Southern Hemisphere ionosphere.
\end{abstract}

Keywords. Ionosphere (Auroral ionosphere; Electric fields and currents) - Magnetospheric physics (Magnetosphereionosphere interactions)

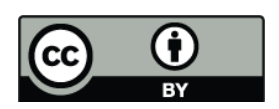

Correspondence to: $\mathrm{O}$. Amm (olaf.amm@fmi.fi)

\section{Introduction}

The study of bursty bulk flows (BBF) in the plasma sheet of the Earth's magnetotail and its boundary layer, and of their ionospheric counterparts in terms of optical and electrodynamic signatures, has been a center of interest in solarterrestrial physics in the recent years. This is due to the crucial importance of BBF for the mass and energy transport in the magnetosphere, and due to the localized and at times extremely strong optical and electromagnetic disturbances that they cause in the ionosphere. The ionospheric signatures can in turn also be used to infer details about the dynamics of the magnetospheric BBF.

In the plasma sheet of the Earth's magnetotail, BBFs are observed as transient fast flows with velocities of several hundreds $\mathrm{km} \mathrm{s}^{-1}$, with a typical duration of the order of 10 min. Within this duration, often distinct flow bursts with a typical timescale of 1 min exist. In the region $-20 R_{\mathrm{E}}<=$ $X_{\mathrm{GSM}}<=-10 R_{\mathrm{E}}$, the majority of the BBF is directed earthwards, and their number decreases towards the inner border of that region, indicative of flow braking in the inner magnetosphere (Baumjohann et al., 1990; Angelopoulos et al., 1992; Schödel et al., 2001). BBF are characterized by a depleted plasma density but increased magnetic field magnitude as compared to their environment ("plasma bubbles"), and are often accompanied by transient dipolarizations of the magnetic field. The dawn-dusk extent of the structures is estimated to $1-3 R_{\mathrm{E}}$ (Sergeev et al., 1996; Nakamura et al., 2004). From a statistical analysis of satellite observations, Angelopoulos et al. (1994) concluded that BBF were responsible for $60-100 \%$ of the Earthward transport of mass, energy and magnetic flux in the part of the observed part of the plasma sheet, while the BBF occurrence only covered 10$15 \%$ of the total observation time.

A conceptual framework to understand BBF and their coupling to the ionosphere was first introduced by Pontius and

Published by Copernicus Publications on behalf of the European Geosciences Union. 


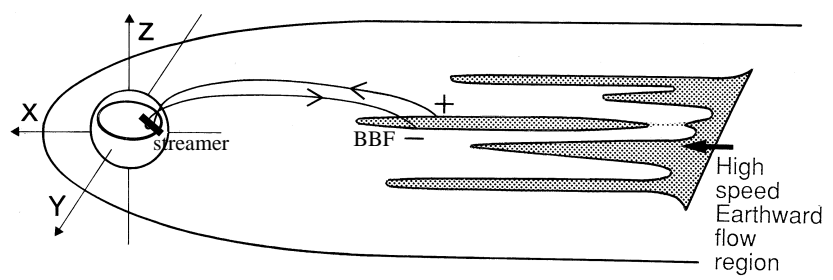

Fig. 1. Schematic sketch of BBF in the plasma sheet of the magnetotail, and their connection to auroral streamers in the ionosphere (from Sergeev et al., 2000, modified).

Wolf (1990), and later refined by Chen and Wolf (1993, 1999). A schematic sketch of the related configuration is shown in Fig. 1. This "bubble model" describes the BBF as a plasma bubble elongated in $X_{\mathrm{GSM}^{-}}$-direction. Since the bubble partially disrupts the cross tail current, space charges are accumulated at the zonal boundaries of the bubble. These space charges set up an enhanced duskward electric field, and thus earthward plasma convection, inside the bubble, while outside of the bubble the plasma flow closes in a double vortex return flow pattern. In order to ensure current continuity at the zonal boundaries of the bubble, downward fieldaligned currents (FAC) are diverted to the ionosphere at its dawnside boundary, and upward FAC and the duskside one. This zonally separated pair of FAC sheets then closes in the ionosphere, forming a narrow current wedge.

From the point of view of ionospheric observations, Henderson et al. (1998) first suggested that finger-like, meridionally elongated auroral forms that protrude equatorward inside the substorm auroral bulge, as they observed them with satellite optical data, are ionospheric counterparts of BBF. This was later confirmed by a statistical investigation of Nakamura et al. (2001). However, they also found that not all BBF cause such "auroral streamers" as their optical ionospheric counterpart, but some of them are rather connected to pseudo-breakup type of auroral signatures, and that the occurrence of auroral streamers is not restricted to the substorm bulge. The initial development of auroral streamers takes place at the poleward boundary of the auroral oval (during substorms: of the substorm auroral bulge), from where they propagate equatorward with typical speeds of $1-5 \mathrm{~km} \mathrm{~s}^{-1}$, thereby often detaching from the poleward boundary. The zonal extent of the auroral streamers is typically of the order of $100-150 \mathrm{~km}$ but can be as narrow as $20 \mathrm{~km}$. When the streamers reach the equatorward boundary of the oval (substorm bulge), they decay by evolving into a patch of diffuse or pulsating aurora. In many cases, several streamers evolve simultaneously with an azimuthal separation of 150$500 \mathrm{~km}$, which together with a typical westward motion of about $1.5 \mathrm{~km} \mathrm{~s}^{-1}$ leads to a recurring appearance of streamers at a ground observation site (Amm and Kauristie, 2002, and references therein).
The first detailed analysis of the ionospheric electrodynamics associated with an auroral streamer and of the relation of the current system to the auroral form as observed by an all-sky camera was performed by Amm et al. (1999). In agreement with the predictions of Chen and Wolf (1993, 1999), they found a wedge-like ionospheric current system to be associated with the streamers, with concentrated upward FAC at the western flank of the auroral structure, and more distributed downward FAC in an area filled with diffuse aurora eastward of the streamer, and the total current flow in a southwestern direction. For this extreme event, maximum Hall conductance values of more than $200 \mathrm{~S}$ and maximum upward FAC magnitudes of up to $25 \mathrm{~A} \mathrm{~km}^{-2}$ have been resulted from the analysis. More detail about this and other earlier works on auroral streamers can be found in the review by Amm and Kauristie (2002).

While Amm et al. (1999), based on combined data from a ground magnetometer network and ionospheric electric field data from a coherent scatter radar, were able to infer total ionospheric currents, often only magnetometer data alone are available from which equivalent currents can be calculated (e.g., Untiedt and Baumjohann, 1993). Using conjugate Cluster satellite and MIRACLE ground-based network data, Nakamura et al. (2005) found that the typical signature of auroral streamers in the equivalent currents is a localized channel of enhanced northwestward pointing currents, where the current amplitude is enhanced with respect to the background westward electrojet. The auroral form and upward FAC are located at the western and southwestern edge of this channel, while the downward FAC area is situated eastward and northeastward of it. This result of a single event study has later been confirmed as a general feature by Juusola et al. (2009) who studied all BBF events seen at Cluster with MIRACLE being located in the conjugate ionosphere during the years 2001-2006. They also found that this typical equivalent current feature is the signature of streamers occurring both during substorms and during non-substorm periods.

From the perspective of magnetospheric observations, using Cluster spacecraft data of a BBF event during a substorm expansion phase, Forsyth et al. (2008) recently arrived at an upward FAC density of $18 \mathrm{~A} \mathrm{~km}^{-2}$ when projected to the ionosphere, comparable to the result of the ground-based analysis by Amm et al. (1999). Their study, as well as a number of other studies based on magnetospheric observations of BBF (e.g., Sergeev et al., 1996, 2000; Nakamura et al., 2005; Snekvik et al., 2007; Takada et al., 2008; Pitkänen et al., 2011) are consistent with the plasma bubble concept of Chen and Wolf $(1993,1999)$. Hence this concept has established itself today as the major guide for the interpretation of BBF/auroral streamer observations.

Even though the knowledge of BBF and auroral streamers has improved significantly over the last decade, there are still a number of open questions concerning these features. In this paper, we study a BBF and auroral streamer event in the recovery phase of a substorm during a double oval 


$$
\text { 2004-09-14, } 2117 \mathrm{UT}
$$
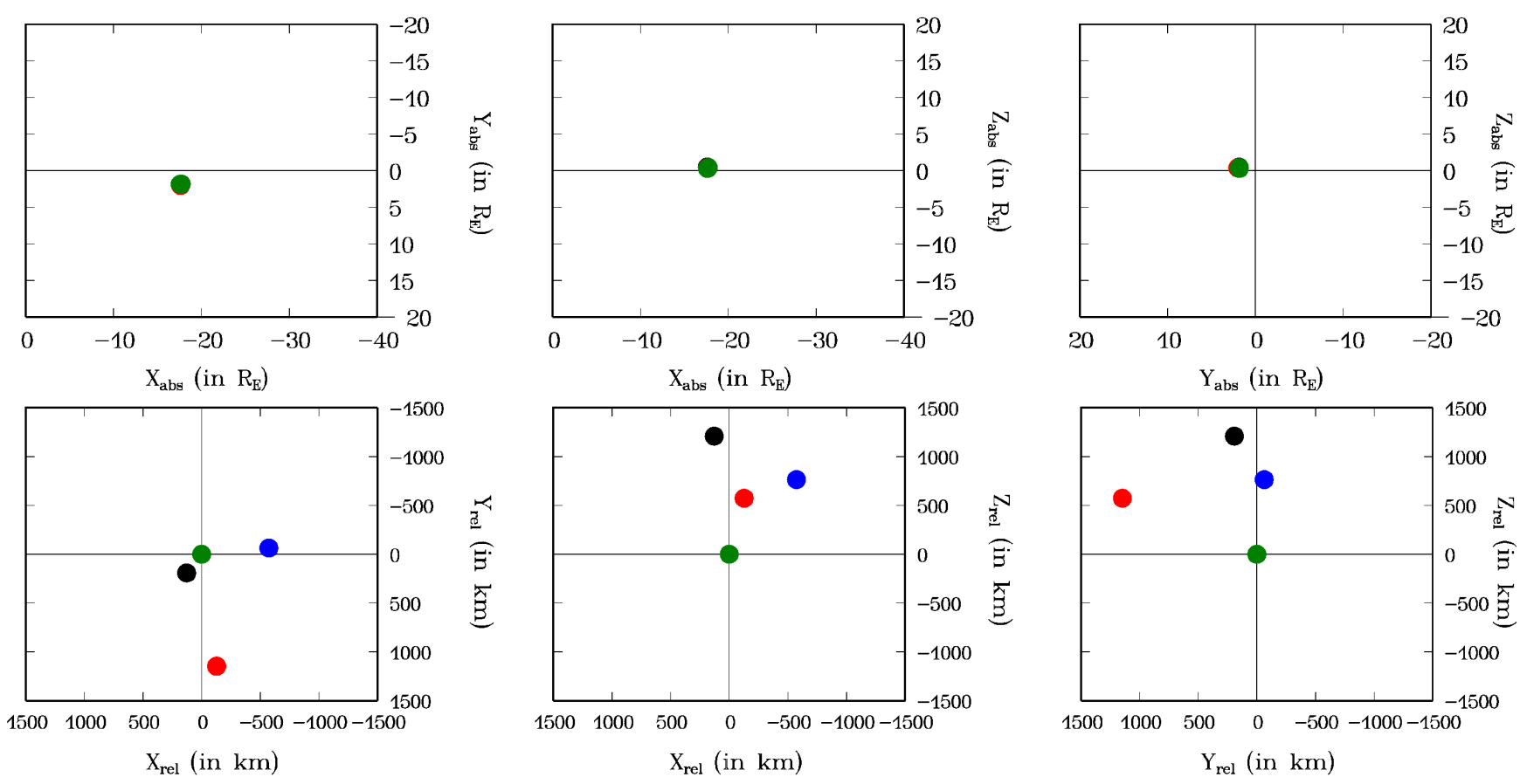

Fig. 2. Location of Cluster spacecraft in GSM coordinates. Upper row: Absolute location in different planes, in $R_{\mathrm{E}}$; Lower row: Relation location in different planes, with Cluster 3 taken as reference, in km (black: Cluster 1, red: Cluster 2, green: Cluster 3; blue: Cluster 4).

configuration on 14 September 2004, at $~ 21: 17$ UT, using conjugate space-based and ground-based data. By that we discuss the following open questions:

- How does the evolution of an auroral streamer depend on the background conditions in the ionospheremagnetosphere system? (Substorm expansion or recovery phase, double oval or not, thin or dense plasma sheet) As most previous conjugate event studies have been carried out with substorm expansion phase events with mostly dense plasma sheets, little is known about this question.

- What amount of current is closed meridionally by the auroral streamer current system in the ionosphere?

- Are auroral streamers taking place simultaneously in the opposite conjugate hemispheres? Up to now, only one single event study by Sergeev et al. (2004), using satellite optical data on the Northern Hemisphere particle precipitation data from a low-orbiting satellite on the Southern Hemisphere, gives an indication that this question is to be answered positively.

In Sect. 2, a brief introduction of the instrumentation used for this study is given. Section 3 shows the space-based and ground-based data sets, and in Sect. 4 we discuss the observations in terms of the abovementioned and other questions. Our main conclusions are summarized in Sect. 5.

\section{Instrumentation}

The Cluster satellite fleet (Escoubet et al., 2001) location and configuration for our event on 14 September 2004, is shown in Fig. 2 for 21:17 UT (in GSM coordinates). Here and in the following, spacecraft 1 is marked with black colour, spacecraft 2 red, spacecraft 3 green, and spacecraft 4 blue. For our study, data from the Fluxgate magnetometer (FGM, Balogh et al., 2001) and Cluster Ion Spectrometry (CIS, Rème et al., 2001) instruments are used. With respect to the CIS, data from the Hot Ion Analyser (HIA) are shown for spacecraft 1 and 3. The four spacecraft are situated in the northern $\left(Z_{\mathrm{GSM}} \sim 0.4 R_{\mathrm{E}}\right)$ near-Earth tail at $X_{\mathrm{GSM}} \sim-17.6 R_{\mathrm{E}}$, in the pre-midnight sector at $Y_{\mathrm{GSM}} \sim 1.8-2 R_{\mathrm{E}}$ (upper row). As can be seen from the relative spacecraft positions shown in the lower row of Fig. 2 (where Cluster 3 has been used as the central satellite), for this event the separation of the Cluster spacecraft was at most $\sim 1200 \mathrm{~km}$ in each dimension, with Cluster 2 being in the most duskward position, and Cluster 3 being situated closest to the equator. Consequently, the Cluster footprints in the northern ionosphere, shown together with the ambient IMAGE ground magnetometer network stations (Viljanen and Häkkinen, 1997) in Fig. 3 in the geographic coordinate system, are falling very close together, when compared to the minimum resolvable scale length of the ground magnetometer network of $\sim 50 \mathrm{~km}$ (e.g., Untiedt and Baumjohann, 1993). The footprints have been calculated 


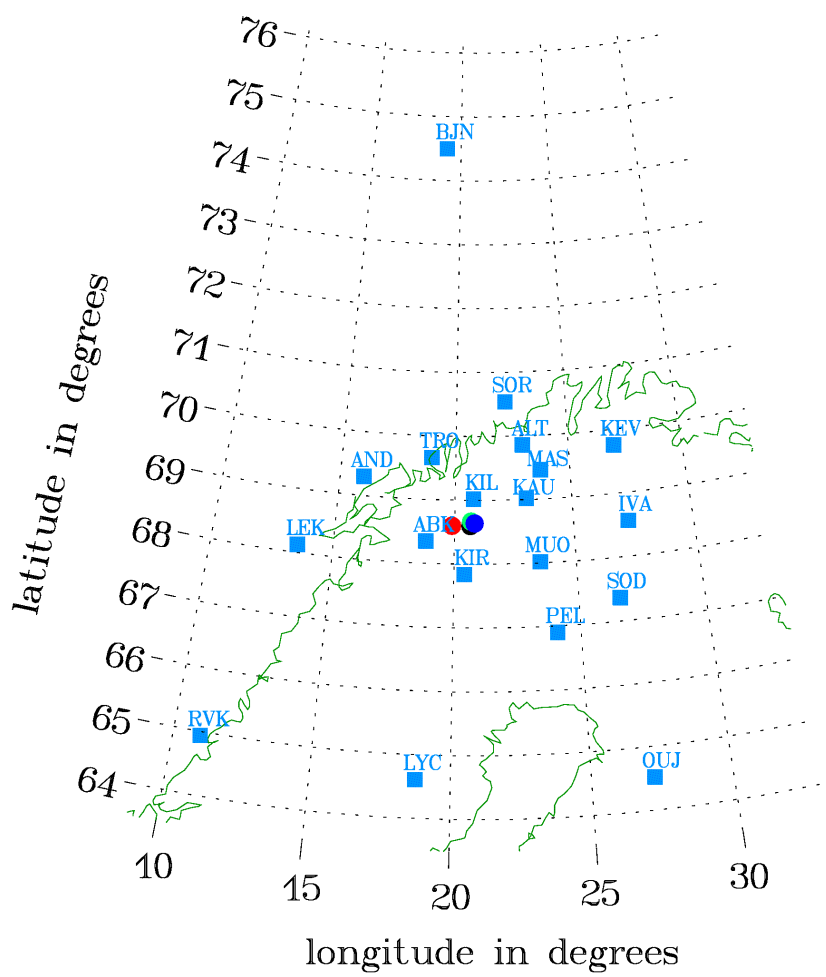

Fig. 3. Map of northern Scandinavia showing the IMAGE magnetometer stations most relevant for this study (blue squares, with station name abbreviations), and the magnetic footprints of the four Cluster spacecraft (circles; black: Cluster 1, red: Cluster 2, green: Cluster 3; blue: Cluster 4).

with the Tsyganenko 89 magnetic field model (T89; Tsyganenko, 1989) under the prevailing value of $\mathrm{Kp}=4$. The validity of the magnetic field modeling using the stated model and parameter has independently been confirmed with the Hybrid Input Algorithm model (Kubyshkina et al., 1999). This model modifies the input to the Tsyganenko model such that it takes into account actual magnetic field measurements from a number of spacecraft in the magnetosphere for our event. The footprints are located in the densest area of the IMAGE station network in the Scandinavian mainland, not far from the EISCAT transmitter station in Troms $\varnothing$.

The ground-based instrumentation for our study consists of the IMAGE magnetometer network (cf. Fig. 3 for the densest part of the network, most relevant for our study) and the European Incoherent Scatter Facility (EISCAT; Folkestad et al., 1983) mainland radar. The radar was operating in a mode such that its VHF beam pointed to approximately geographic north direction, with an elevation angle of 30 degrees. Further, the Far Ultraviolet Wideband Imaging Camera (WIC) on the IMAGE satellite monitors the auroral emissions in the spectral range of 140-190 nm (Mende et al., 2000), in the Southern Hemisphere area conjugate to the Cluster location.

\section{Observations}

Figure 4 shows selected data of the Cluster satellites on 14 September 2004, between 21:10 and 21:25 UT. The colour scheme referring to each satellite is the same as in Fig. 3. (Note that not every data type is available on every satellite, due to instrumental issues.) Our main interest focuses on the interval between $\sim 21: 14: 50-21: 18 \mathrm{UT}$, which is marked by the red frame in Fig. 4. This period is characterized by a clear increase in the Earthward plasma velocity $V_{\mathrm{X}, \mathrm{GSM}}$ (panel 4 of Fig. 4), seen both by Cluster 1 and Cluster 3 (no velocity measurements are available on Cluster 2 and 4), up to a maximum of $\sim 200 \mathrm{~km} \mathrm{~s}^{-1}$ at Cluster 1 . While this maximum velocity is smaller than observed in other BBF cases (e.g., Nakamura et al., 2005), probably due to Cluster not being located in the very center of the flow for our event (see below), the Earthward velocity increase is very well isolated and has a duration of $\sim 3 \mathrm{~min}$, in line with earlier BBF observations (cf., Amm and Kauristie, 2002, and references therein). The other two velocity components (panels 5 and 6) show comparably small deviations. Before and in the beginning of the fast flow, the Cluster satellites are located in the Northern Hemisphere of the magnetosphere, as indicated by the positive $B_{\mathrm{X}, \mathrm{GSM}}$ magnetic field component (panel 1). During the fast flow event, Cluster entered the region close to the magnetic equator of the magnetosphere, while after the event it was again clearly positioned in the Northern Hemisphere. The fast flow period is associated with two dipolarizations as seen by the quick increases of the $B_{\mathrm{Z}, \mathrm{GSM}}$ component (panel 3). This is a typical feature observed during BBF periods (e.g., Nakamura et al., 2002). The overall large value of $B_{\mathrm{Z}, \mathrm{GSM}}$ indicates that the plasma sheet is thick (in size) during our event. The decrease of $B_{\mathrm{Y}, \mathrm{GSM}}$ (panel 2) before and in the beginning of the fast flow event is indicative for magnetic shear related to field-aligned currents (FAC) flowing at the border of the BBF region (cf., Nakamura et al., 2005).

Panel 7 of Fig. 4 shows the GSM components of the currents, as calculated with the curlometer technique (Dunlop et al., 2002). At the bottom of panel 7, the computational result for $\operatorname{div} B / \mu_{0}$ (which ideally should be zero) is displayed in the same scale as the currents, providing an error estimate for the technique. Clearly, the currents are becoming stronger and more variable during the fast flow event, and continue to be so also after the event. However, due to the small Cluster spacecraft separations in 2004, when mapped to the ionosphere these currents refer to scales smaller than the spatial resolution available from our ground-based instrumentation, which is $\sim 50 \mathrm{~km}$ in the densest part of the IMAGE magnetometer network. Since the focus of this paper lies in the discussion of observations of an auroral streamer with the scale sizes as observable in the ionosphere, we do not interpret these currents in any detail.

The ion density (panel 8 of Fig. 4) is on the order of $0.25 \mathrm{~cm}^{-3}$ at Cluster 1 and Cluster 3 throughout the period 


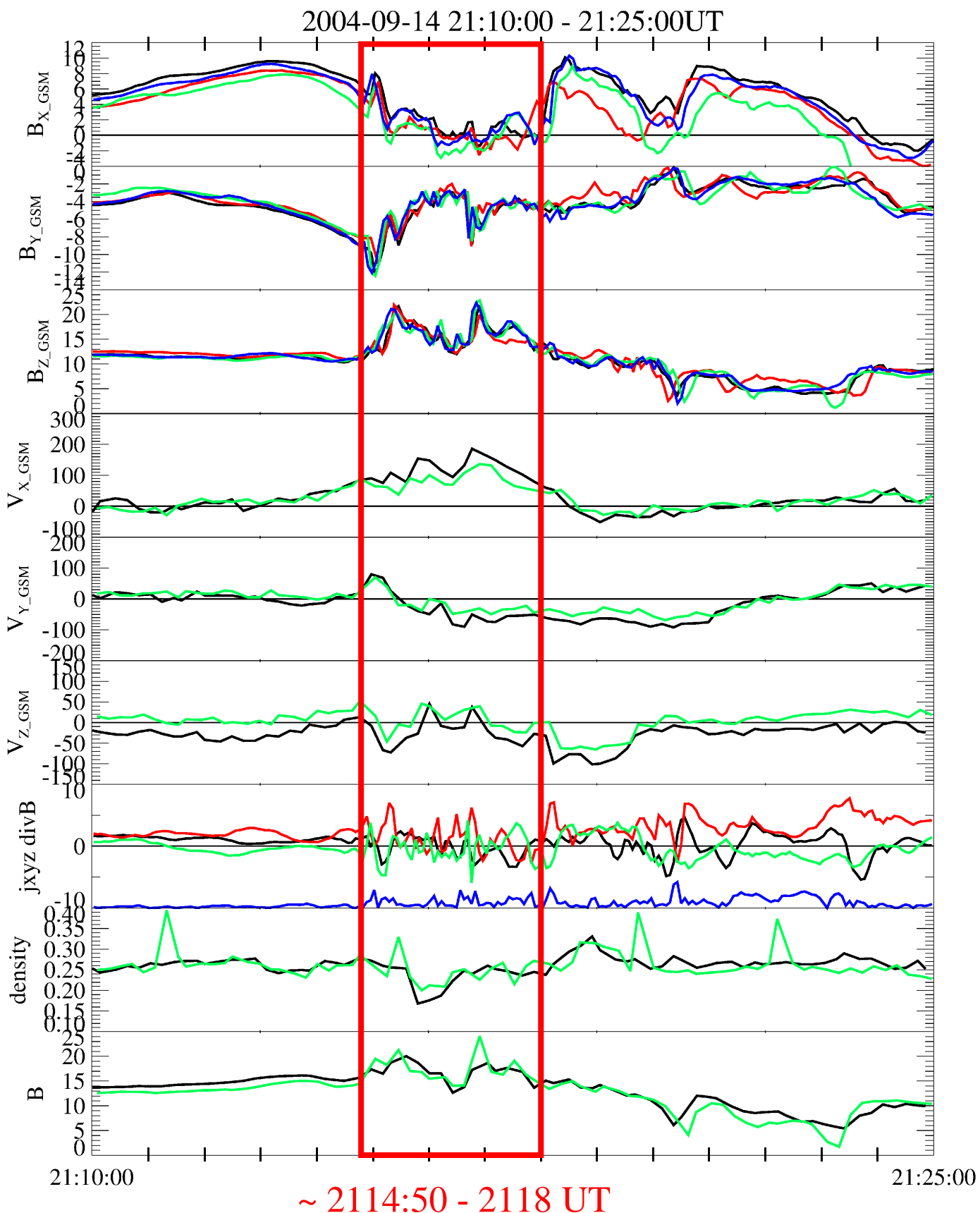

Fig. 4. Cluster data overview, with the BBF event period marked by the red box. Directions in GSM coordinate system. Panels 1-3: magnetic field, in nT; Panels 4-6: ion velocity, in $\mathrm{km} \mathrm{s}^{-1}$ (black: Cluster 1, red: Cluster 2, green: Cluster 3; blue: Cluster 4); Panel 7: currents as determined by the "curlometer" technique, in $\mathrm{nA} \mathrm{m}^{-2}$ (black: $\mathrm{X}$, red: Y, green $\mathrm{Z}$-direction) and computationally resulting divergence of $\mathrm{B}$ (blue), in $\mathrm{nA} \mathrm{m}^{-2}$; Panel 8: ion density, in $1 \mathrm{~cm}^{-3}$; Panel 9: total magnetic field, in $\mathrm{nT}$.

before and after the BBF event displayed in Fig. 4. We can thus speak of a configuration with a comparably thin (in density) but thick (in size) plasma sheet. During the fast flow period, on average we observe a decrease in the ion density, and thus of thermal pressure as the temperature varies only marginally (not shown), and simultaneously a clear increase of the total magnetic field strength $|B|$ (panel 9 of Fig. 4), and thus of magnetic pressure. Both of these features are typical signatures of a plasma bubble (e.g., Sergeev et al., 1996). Thus we conclude that Cluster indeed sees a BBF event during the abovementioned time period. 

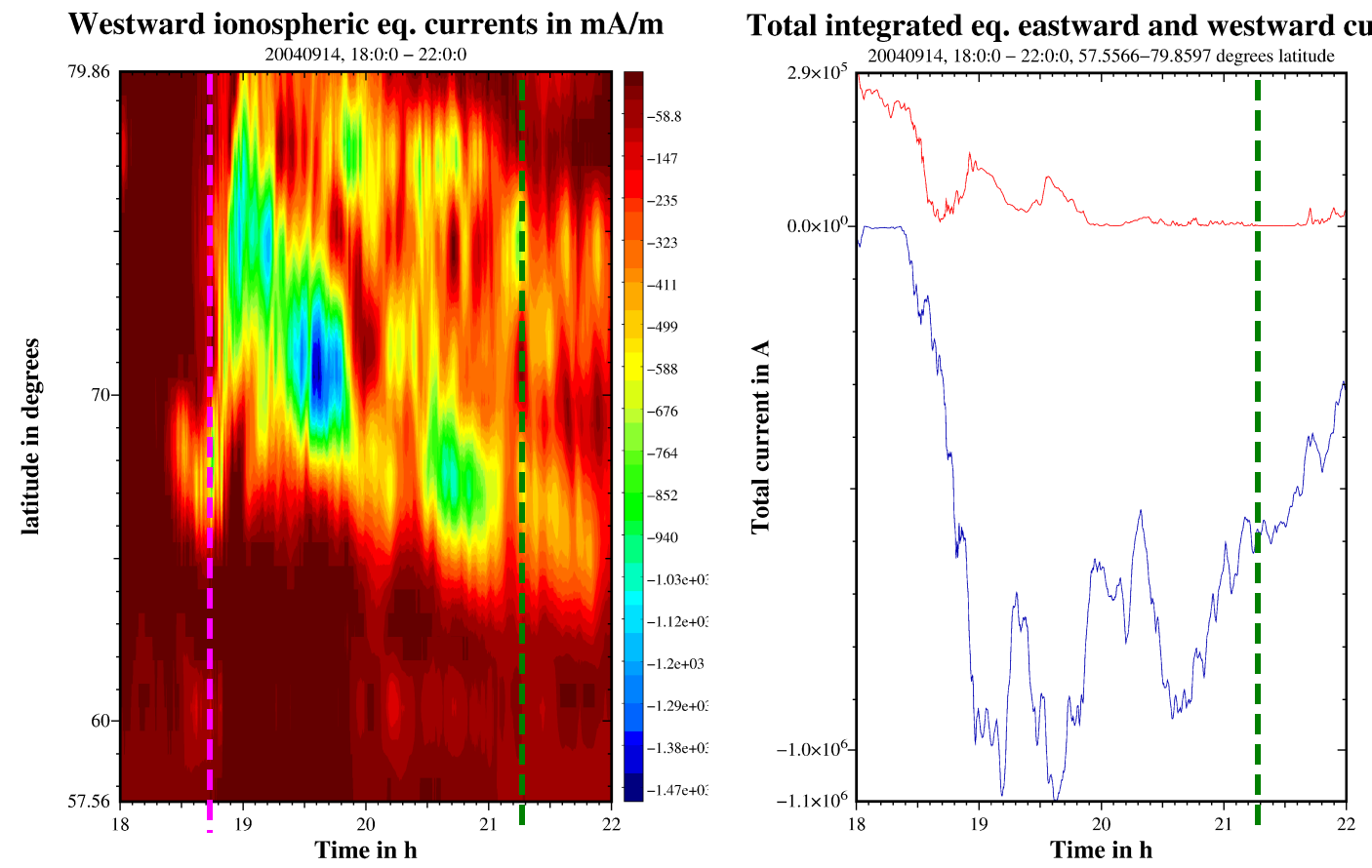

Fig. 5. Keogram-style overview of ionospheric equivalent current development during the substorm within which our BBF event occurred. (The time of the BBF event studied in this paper is marked by green dashed line.) Left panel: westward component of ionospheric equivalent currents as a function of geographic latitude and time (substorm onset is marked by the red dashed line); right panel: total meridionally integrated westward (blue) and eastward (red) currents as a function of time, in A.

In the following, we describe the ionospheric observations in the vicinity of the magnetic footprints of the Cluster satellites, during the BBF event. Figure 5 shows the overall development of the substorm during which our event occurred in a keogram-type style, by displaying the east-west component of the ionospheric equivalent currents (left panel), based on ground magnetometer data from a meridional chain of IMAGE magnetometer stations, as a function of time. For the calculation of the ionospheric equivalent currents, the technique of Vanhamäki et al. (2003) has been used which implicitly assumes no zonal gradients of the currents or magnetic fields. While this assumption is certainly not strictly valid over the whole 4-h period from 18:00-22:00 UT displayed, the results of this technique still give a good overview over the dynamical evolution of the current systems during that period. Note that for clarity, in the left-hand panel only the westward component of the currents is shown, as we are concentrating on the evolution of the currents inside the substorm bulge where westward directed currents prevail. The right-hand side of Fig. 5 shows the meridionally integrated (over the full range of latitudes shown in the left panel) total current as a function of time, where westward (blue line) and eastward (red line) current is integrated separately.

On the left-hand panel of Fig. 5, we recognize the equatorward movement of a westward current related to the growth phase until about 18:43 UT when a substorm onset occurs (marked by the pink vertical line). Subsequently, the currents rapidly expand poleward and the meridional extent of westward current flow widens, with substantial westward currents reaching the poleward boundary of the analysis area located at $\sim 79.9^{\circ}$ latitude at 19:00 UT, more than $10^{\circ}$ poleward of the onset latitude. After this initial expansion phase of the substorm, a recovery phase is seen during which the currents over several hours slowly retreat equatorward and weaken. The strongest meridionally integrated current within our analysis area amounts to $~ 1.1$ MA during this substorm. The equatorward motion of the currents continues at the end of the time period presented here, and thus the recovery phase has still not ended until 22:00 UT.

During the recovery phase, we can clearly identify two meridionally separated areas which show enhanced westward currents: One is located close to the poleward boundary of the overall area with enhanced currents (and thus of the substorm bulge), and another one close to its equatorward flank. In between these two areas, a region with significantly decreased westward current is observed. Although the details of this feature vary considerably with time, it is seen throughout the whole recovery phase. This is what we refer to as a "double oval configuration" here. Such a configuration has been reported in terms of the auroral emission seen from satellite observations already by, e.g., Elphinstone et al. (1995), and according to a recent statistical study by Gjerloev et al. (2008), it is a rather typical configuration during substorms. The time of the BBF event as observed by the 

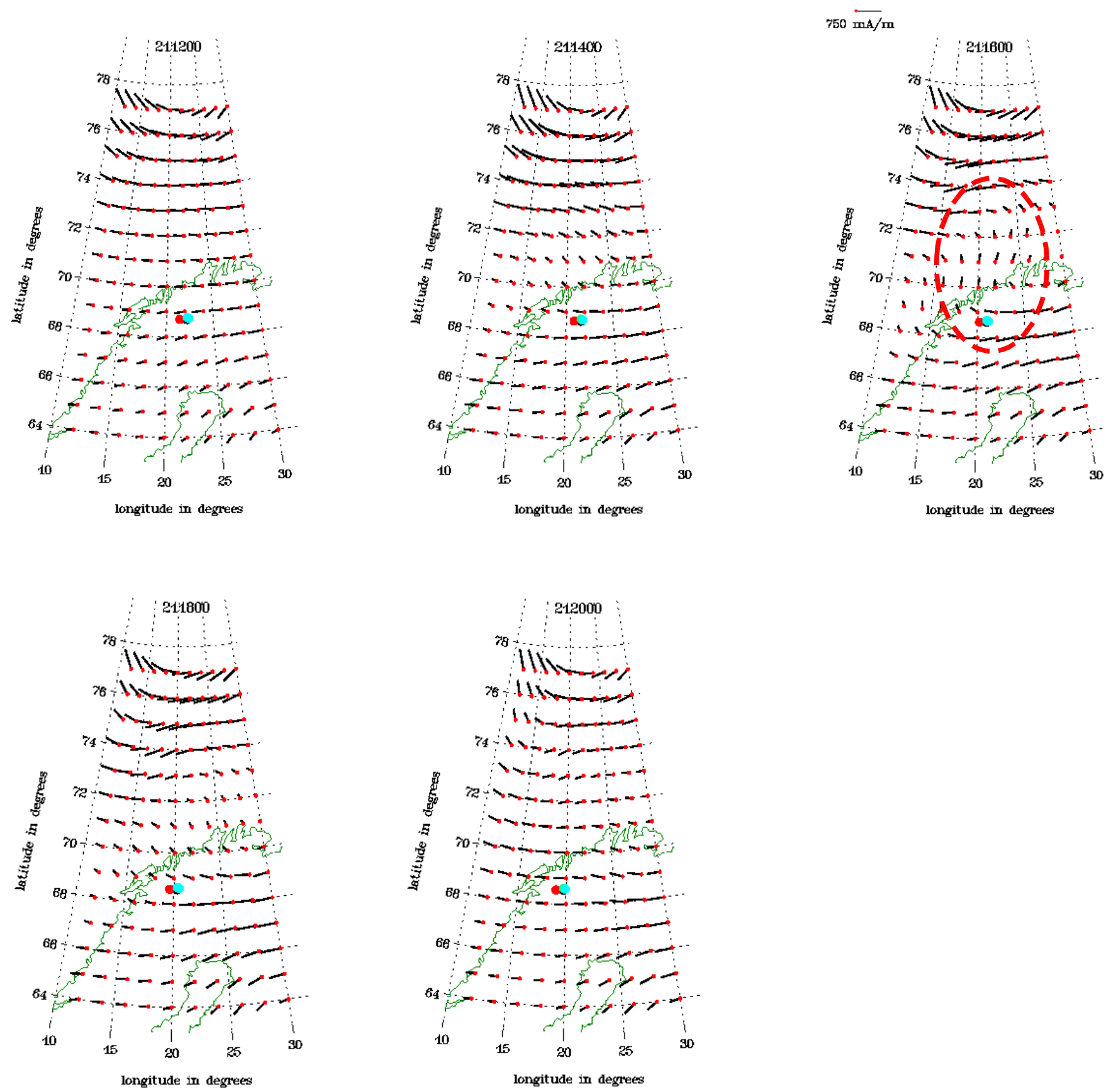

Fig. 6. Spatial maps of ionospheric equivalent currents (in $\mathrm{mA} \mathrm{m}^{-1}$ ) for the time around the BBF event under study. The coastline of northern Scandinavia and the Cluster footprints are marked as in Fig. 3. The main signature of the BBF event in the 21:16 UT panel is marked by a dashed ellipse.

Cluster spacecraft around 21:17 UT is marked by the green dashed vertical lines in Fig. 5. Thus the event occurs about $21 / 2 \mathrm{~h}$ after the substorm onset during its recovery phase, while a double oval configuration existed.

From the keogram-type results as shown in Fig. 5, it is very difficult to perform any detailed analysis of the ionospheric signature of the BBF event. Shortly before the event, an increase of westward current is seen at $\sim 75^{\circ}$ lat, while during the event, the most prominent feature is a clear decrease of the westward current component at $\sim 71^{\circ}$ lat. Shortly after that, again an increase of westward currents is seen at $\sim 68^{\circ}$ lat. However, the ionospheric signature of the BBF becomes very clear when spatial maps of the ionospheric equivalent currents are inspected (Fig. 6), as they 

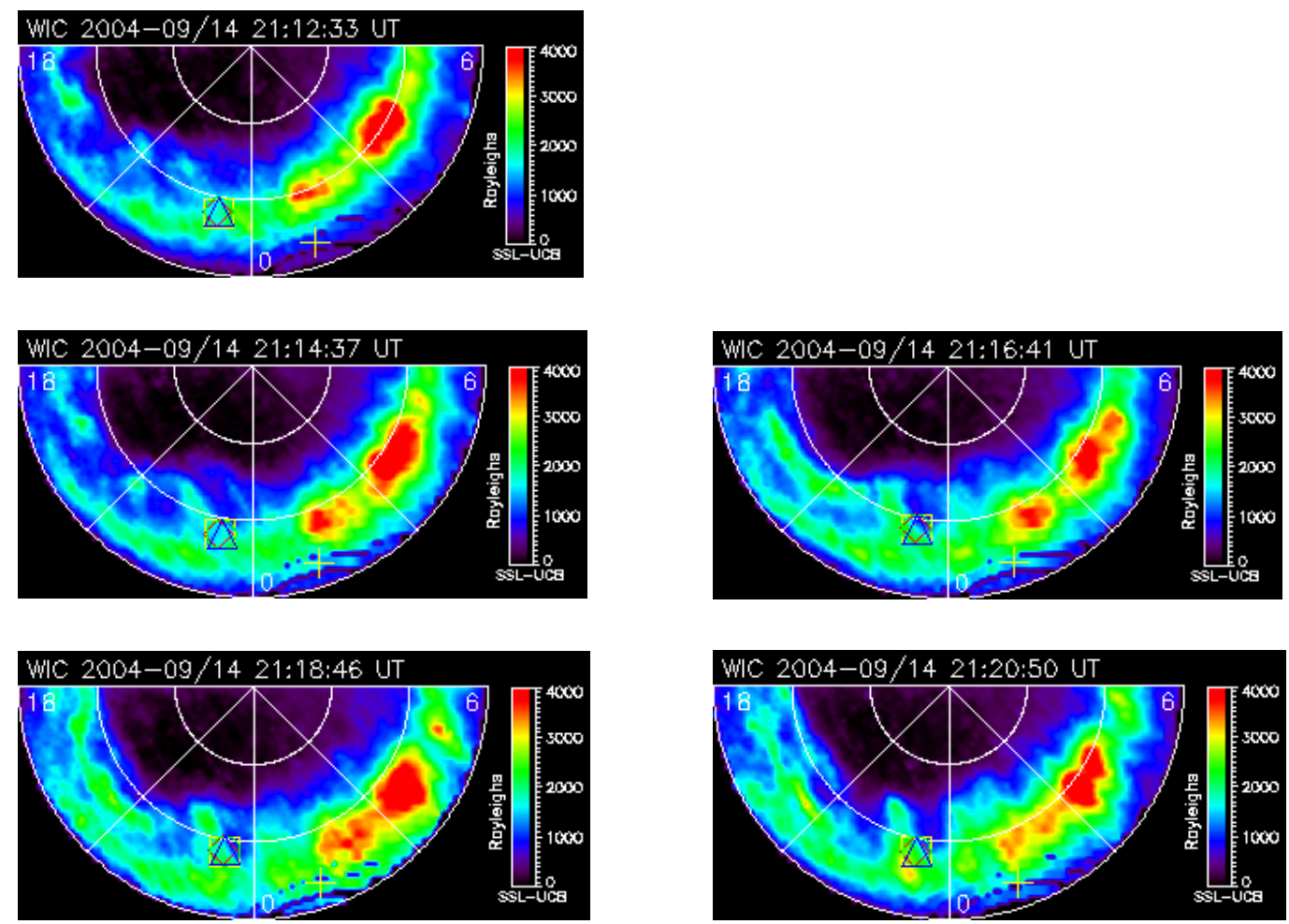

Fig. 7. Maps of ionospheric UV emissions (in R) on the Southern Hemisphere for the time around the BBF event under study. The Cluster footprints are marked by the coloured squares and triangles (which due to the scale of the map and the short Cluster spacecraft separations in 2004 appear to lie on top of each other in the figure).

are generated from the ground magnetic data using the technique by Amm and Viljanen (1999). In the figure, also the magnetic footprints of the Cluster spacecraft are marked. At 21:12 UT, before the BBF event, the currents are mostly fairly uniformly directed westward with amplitudes around $300 \mathrm{~mA} \mathrm{~m}^{-1}$. Only at the poleward edge of our analysis area, where in agreement with Fig. 5 the largest currents are observed within the poleward part of the double oval, some vorticity is seen. At 21:14 UT, a poleward component is already seen in the equivalent currents around the longitude of the Cluster footprints between $\sim 70-73^{\circ}$ lat. At 21:16 UT, during the observation of the BBF at Cluster, this poleward component reaches to the Cluster footprint latitudes of $\sim 69^{\circ}$ lat, while in the area poleward of them, the equivalent currents now point predominantly northward with amplitudes of the order of $250 \mathrm{~mA} \mathrm{~m}^{-1}$. At the end of the BBF event in Cluster at 21:18 UT, this northward component diminishes again, until at 21:20 UT the equivalent currents return to a configuration almost identical to the one of 21:12 UT from before the BBF event, with the exception that the westward currents in the equatorward portion of the double oval have intensified, again in agreement with Fig. 5. Hence, the spatial maps reveal a very distinct signature of the ionospheric equivalent currents in response to the BBF in the magnetosphere, namely a northward turning of the currents in the latitude range between the two portions of the double oval $(\sim 69$ $73^{\circ}$ lat), within a limited range of longitudes $\left(\sim 14-26^{\circ}\right.$ lon). Note that in geomagnetic coordinates, the streamer current channel is not exactly aligned in meridional direction. This is a typical case for auroral streamers and their associated current system (e.g., Amm and Kauristie, 2002; Juusola et al., 2009).

Figure 7 shows observations of the UV emissions on the Southern Hemisphere, made by the WIC on the IMAGE satellite, for approximately the same time interval and with approximately the same time resolution as used with the equivalent currents in Fig. 6. The plots are shown with magnetic latitude and magnetic local time (MLT) coordinates. The magnetic footprints of the Cluster spacecraft are marked by the colour symbols in the figure. In the evening to midnight sector, the double oval configuration is clearly visible in all images, even though it does not appear to exist without spatial interruptions over a wide range of MLT for every of the timesteps shown. An auroral streamer starts to be clearly visible in the image of 21:14:37 UT, and it has reached the equatorward portion of the double oval and the Cluster magnetic footprints at 21:16:41 UT. Starting from 21:18:46 UT and very clearly visible at 21:20:50 UT, a blob of UV emission forms at the base of the auroral streamer when it meets the equatorward portion of the double oval. This blob remains visible until $\sim 21: 30$ UT (data not shown). 

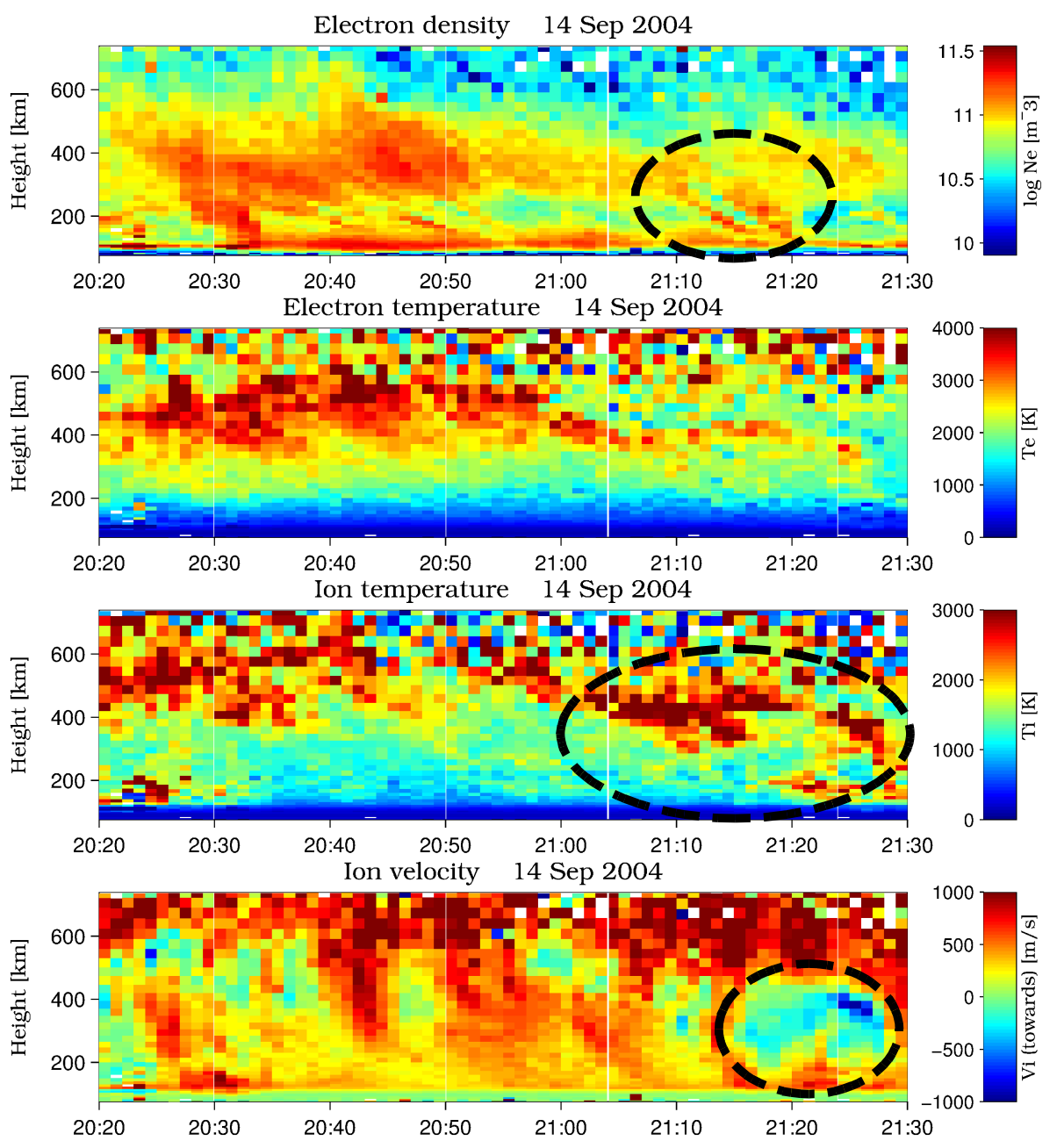

Fig. 8. EISCAT data overview for the time around the BBF event under study. Panel 1: electron density, in $1 \mathrm{~m}^{-3}$. Panel 2 : electron temperature, in K. Panel 3: ion temperature, in K. Panel 4: ion drift velocity component along the radar beam, positive towards the radar, in $\mathrm{m} \mathrm{s}^{-1}$. All plots as function of time and altitude.

It should be noted that the double oval structure is not seen everywhere very clearly in the IMAGE WIC data in Fig. 7, and also Fig. 5 shows that the magnitude of the currents varies strongly in both parts of the double oval throughout the substorm. However, it is important to notice that even during periods of weaker current magnitudes, meridional profiles of the equivalent currents still exhibit the double oval structure. For our event, this is also seen from the equivalent current maps shown in Fig. 6.

Finally, Figs. 8 and 9 present the EISCAT observations for our event. In Fig. 8, the observations are presented in a colour plot as functions of altitude and time, and in Fig. 9 as in a surface plot as functions of latitude and time. Since the radars's beam was pointing with an elevation angle of 30 degrees towards approximately geographic north, for each moment of time an increasing altitude in Fig. 8 corresponds to an observation at an increasing latitude, and an increasing latitude in Fig. 9 corresponds to an increasing altitude. We focus our discussion here to the immediate signatures related to the auroral streamer/BBF event. Most clearly seen in Fig. 9 is a pronounced double peak of enhanced electron density (upper panel of Fig. 8, upper panel of Fig. 9), which starts to be observed moving equatorward from the background F-layer signature at $\sim 21: 12 \mathrm{UT}$ at $\sim 74^{\circ}$ lat. This double peak reaches the most equatorward observation point of the EISCAT beam at $\sim 71.2^{\circ}$ lat in the E-region altitude around 21:20 UT. The red dashed line in Fig. 9 marks the beginning of the Cluster BBF observations at 21:14:50 UT. Even though more patchy, a corresponding increase in the ion temperature (third panel of Fig. 8, bottom panel of Fig. 9) is observed which can be interpreted as caused by ion heating due to an enhanced electric field. It is interesting to note that there is a time delay of $\sim 5$ min between the arrival of the enhanced electron density and the enhanced electric field at the lowest/most equatorward observation point of the EISCAT beam (at $\sim 21: 19 \mathrm{UT}$ and $\sim 21: 24 \mathrm{UT}$, respectively). The signature 

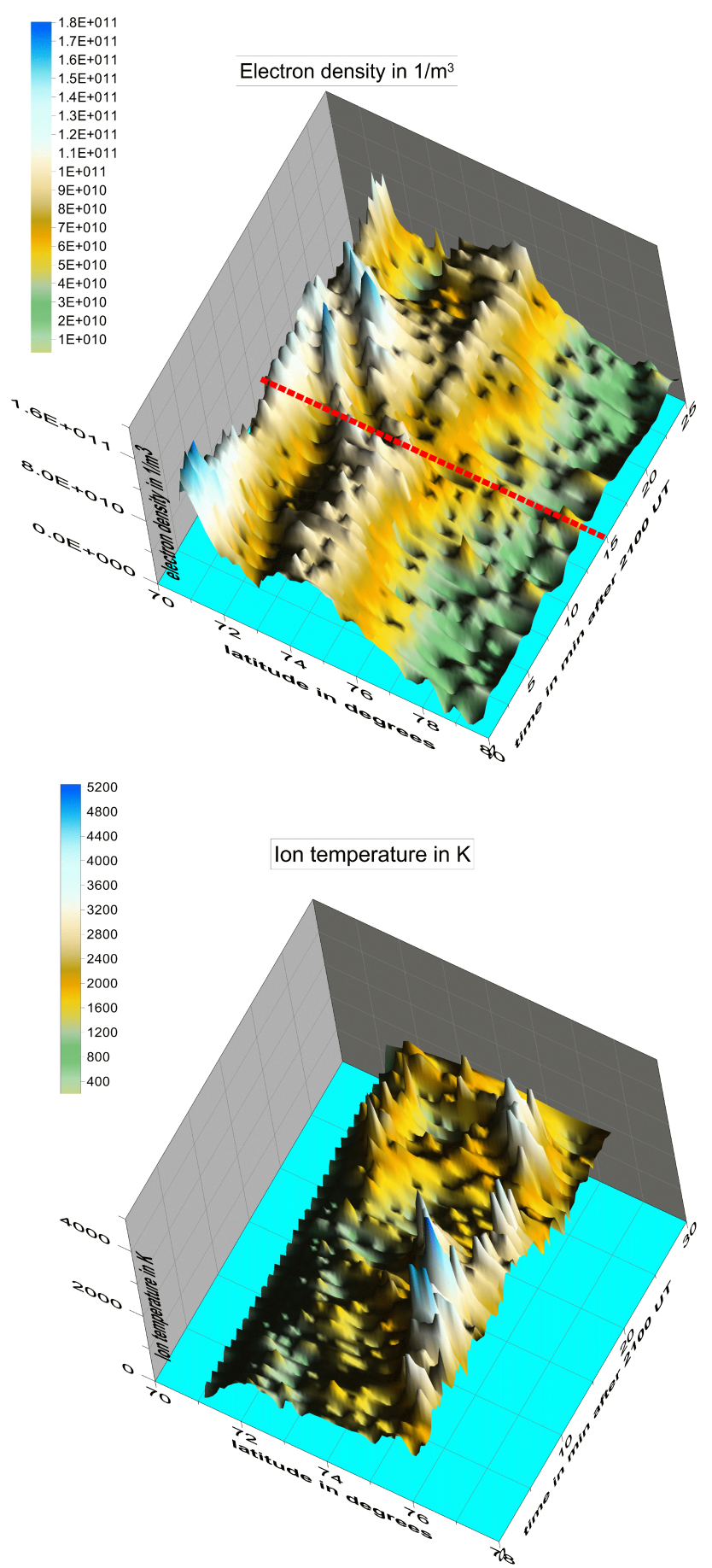

Fig. 9. Contour plots of the electron density (left panel, in $1 \mathrm{~m}^{-3}$ ) and the ion temperature (right panel, in $\mathrm{K}$ ), as a function of time and geographic latitude. The start of the BBF observations in the Cluster spacecraft is marked by the red dashed line in the left panel.

in the electron temperature (second panel of Fig. 8) is less clear. Throughout the lower F-region, an enhanced ion drift velocity along the radar beam in poleward direction is visible, starting from $\sim 21: 16 \mathrm{UT}$, and lasting until $\sim 21: 28 \mathrm{UT}$.
Within the limits of uncertainty given by the observations in opposite hemispheres, this feature is spatially and temporally well collocated with the abovementioned blob of aurora seen in the WIC data (Fig. 7), which starts to develop in the equatorward portion of the double oval once it is reached by the auroral streamer.

\section{Discussion}

Even though there are some differences to previous observations of auroral streamers in terms of ionospheric equivalent currents which are discussed below, both from the timing and location with respect to the Cluster observations of the $\mathrm{BBF}$, and from the observed pattern of a channel of equivalent current with enhanced northward component (cf. Juusola et al., 2009), the observations shown in Fig. 6 around 20:16 UT clearly represent the ionospheric equivalent current signature of an auroral streamer in the Northern Hemisphere, caused by the magnetospheric BBF. While from the experience obtained from earlier studies as mentioned in the introduction, already this signature alone would be a sufficient evidence for the existence of an auroral streamer in the Northern Hemisphere, in addition also the EISCAT electron density observations clearly confirm this (compare, e.g., with the study by Pitkänen et al., 2011). A comparison with the Southern Hemisphere optical data shown in Fig. 7 taken at the same time, which show a well-developed auroral streamer, hence immediately confirms that the auroral streamer takes place simultaneously in the opposite conjugate hemispheres, for this event.

In order to obtain an order-of-magnitude estimate of how much current is carried by the auroral streamer in the meridional direction between the poleward and the equatorward portion of the double oval, we use the following approach: for the latitude at which the largest northward equivalent current component occurred, we integrate this northward component over the range of longitudes for which the amplitude of the northward component is at least $20 \%$ or more than the average amplitude of the westward electrojet located equatorward of the streamer region. Figure 10 (left panel) shows a section of the ionospheric equivalent currents in the area between the two parts of the double oval at 21:17 UT, when the signature of the streamer was most pronounced. The procedure described above results in integration of the northward component of the equivalent currents over the area marked by the red box. The resulting total meridional current associated with the streamer is $\sim 80 \mathrm{kA}$. We should mention that since we are integrating over equivalent, not true, currents, this value does not reflect the true total meridional current, but should be interpreted as an approximation of the meridional flowing Hall current associated with the streamer. In the case that the gradients of the ionospheric conductivity are parallel to the electric field direction, the equivalent currents exactly depict the Hall currents (Amm et al., 2002). 

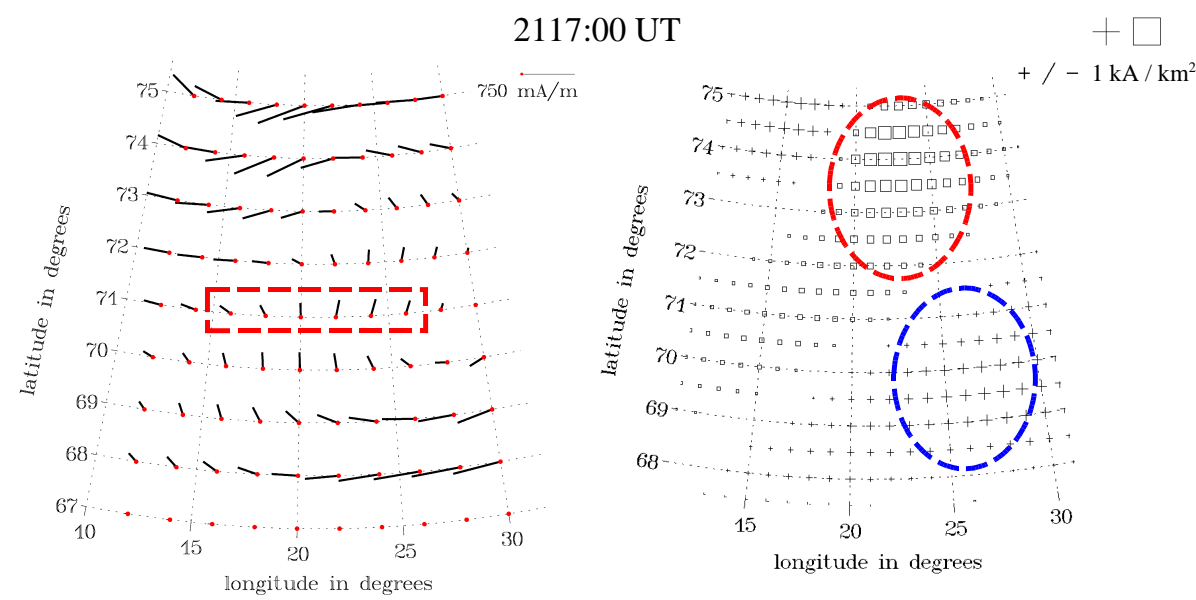

Fig. 10. Left panel: detail of ionospheric equivalent currents map at 21:17 UT. The area enclosed by the red dashed rectangle is used for the integration of the total meridional equivalent current carried by the auroral streamer; right panel: curl of the equivalent currents shown in the left panel. Prominent areas of positive and negative curl are marked by blue and red ellipses, respectively.

(Note that a poleward flowing Hall current means equatorward flowing electrons.) If the ionospheric electric field can be described as the magnetospheric electric field expected by the bubble model mapped to the ionosphere, this condition is expected to be fulfilled to a good approximation (Amm and Kauristie, 2002). For comparison, applying the same procedure as described above to the substorm expansion phase streamer event analysed by Amm et al. (1999) results in a total meridional current of $\sim 288 \mathrm{kA}$. This indicates that the meridional current carried by a recovery phase streamer, as in the present event, is smaller than that carried by an expansion phase streamer, just like the overall currents in the recovery phase are weaker than in the expansion phase (see Fig. 5, right panel).

Inspecting the situation at 21:17 UT between the two portions of the double oval further, the right panel of Fig. 10 shows the vertical component of the curl of the ionospheric equivalent currents. Under the same condition as discussed above, a negative curl (squares) would be proportional to upward FAC, and a positive curl (crosses) would be proportional to downward FAC. For our double oval streamer case, we observe a configuration that is dominated by a patch of negative curl around the area where the streamer intersects with the equatorward boundary of the poleward portion of the oval, and a patch of positive curl around the area where the streamer intersects with the poleward boundary of the equatorward portion of the oval (see the areas marked by red and blue ellipses in the right panel of Fig. 10). These two patches have only a very small zonal displacement from one another. This configuration is clearly different from the one observed in several cases where no double oval was present, where typically a patch of positive curl was located northeastward of another patch of negative curl (e.g., Amm et al., 1999; Nakamura et al., 2005; Juusola et al., 2009). Regarding the equivalent current pattern itself, this difference means that in the "standard case" without a double oval, the typical signature of an auroral streamer is a channel of northwestward directed equivalent currents with typically an anticlockwise vortical structure at the southwestern flank of the channel, as seen in the abovementioned papers. On the other hand, in our "double oval" case we see a channel of almost completely poleward directed equivalent currents which does not show a clear vortical structure at its flank (Fig. 6, panel at 21:16 UT).

In the remaining part of this section, we attempt to provide a possible explanation for this observed difference between the "standard case" and the "double oval" case streamer, which both is in accordance with the EISCAT observations and the observed difference in the equivalent current patterns as outlined above. It should be emphasized that because our data set does not allow for a complete description of the ionospheric electrodynamics of the streamer (most notably, information of the spatial distribution of the ionospheric electric field is missing), nor for a complete description of the magnetospheric situation, this explanation needs to be considered on the level of a hypothesis.

Figure 11 shows a sketch of the ionospheric projection of the double oval situation, with an auroral streamer protruding in equatorward direction. The region between the poleward and the equatorward portion of the oval, both marked as blue rectangles, is considered to have a lower plasma density in the magnetosphere than both of the oval parts, and also the conjugate ionospheric region in between the ovals has a lower conductivity than the ovals. This is in accordance with the reduced auroral luminosity in this intermediate region (cf. Fig. 7). In between the two oval parts, the auroral streamer in the ionosphere is sketched as a north-south aligned channel of enhanced conductivity, also in agreement with the auroral luminosity as shown in Fig. 7, and with the previous studies mentioned in the introduction. It should be noted that from a 


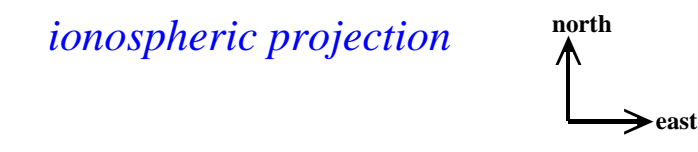

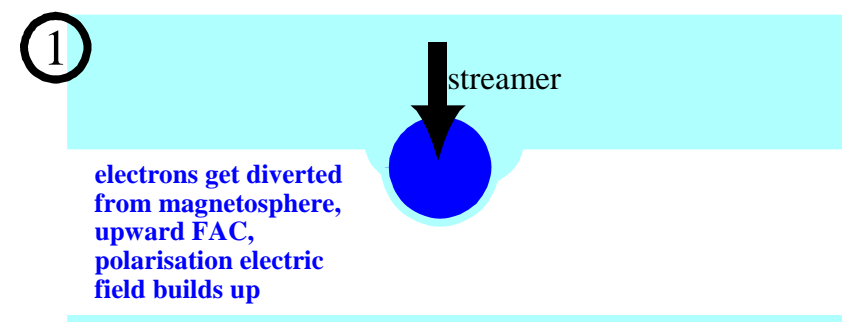

\section{poleward portion of oval \\ low conducting region between ovals $(\triangleq$ low density area in tail plasma sheet)}

\section{equatorward portion of} oval

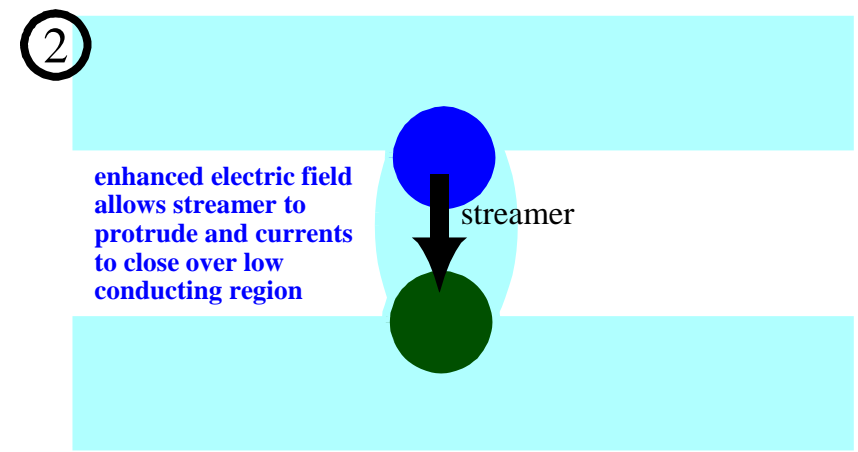

\author{
poleward portion of \\ oval \\ low conducting region \\ between ovals $(\Delta$ low \\ density area in tail \\ plasma sheet) \\ equatorward portion of \\ oval
}

Fig. 11. Schematic sketch of our proposed model to for the evolution of the auroral streamer during a double oval situation (for more details see text).

magnetospheric point of view, the auroral streamer connects to the dawnward flank of the plasma bubble associated with the BBF in the plasma sheet magnetotail. Thus, in our ionospheric projection the plasma bubble itself which has lower density than its surroundings maps to the low-conductance region eastward of the auroral streamer (e.g., Nakamura et al., 2005).

The increased ion heating, corresponding to an increased electric field, as observed by the EISCAT radar in association with the auroral streamer (cf. Figs. 8 and 9) is interpreted as a polarization electric field which is built up when the BBF in the magnetosphere, together with its associated current system, tries to enter the low conducting/low density region between the two double oval portions (upper panel of Fig. 11). Note that this type of situation resembles the mechanism which Chen and Wolf $(1993,1999)$ have proposed for the zonal flanks of a BBF, but turned around by 90 degrees. In the Chen and Wolf $(1993,1999)$ model, the polarization electric field is caused by the inhibition of the cross tail currents at the zonal flanks of the BBF, and thus a zonal electric field is generated. In our double oval model, the BBF current system itself is inhibited at the equatorward edge of the poleward portion of the double oval, and thus a meridional polarization electric field is generated. Since the meridional part of the streamer's current system is carried by equatorward flowing electrons (e.g., Kauristie et al., 2000), the resulting polarization electric field is pointing poleward. Once this polarization electric field has been built up, it allows the streamer's current system to cross through the low conductivity area in between the double oval portions (lower panel of Fig. 11). A displacement between the electron density and the ion heating/electric field enhancement signatures as observed by EISCAT is generally consistent with this process.

In order to test the consistency of such an additional polarization electric field with the observed difference in equivalent currents for "standard" and "double oval" streamers as pointed out above, Fig. 12 presents a conceptual model of the different components of the ionospheric electrodynamics that are involved with an auroral streamer in the two cases, and their associated equivalent current signatures. The term "conceptual" refers to the fact that the goal of this model is not to represent every single detail of the observations (which in its full detail may be a superposition of many complicated features), but to check whether or not the main structure of 


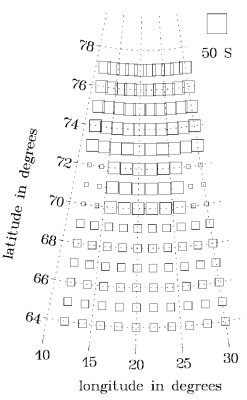

\section{streamer wedge system}
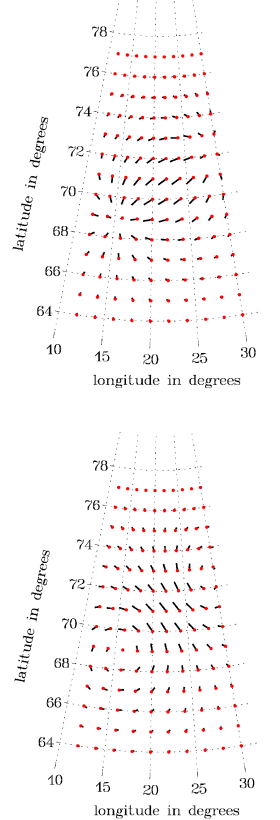

(1)

\section{background electrojet system}
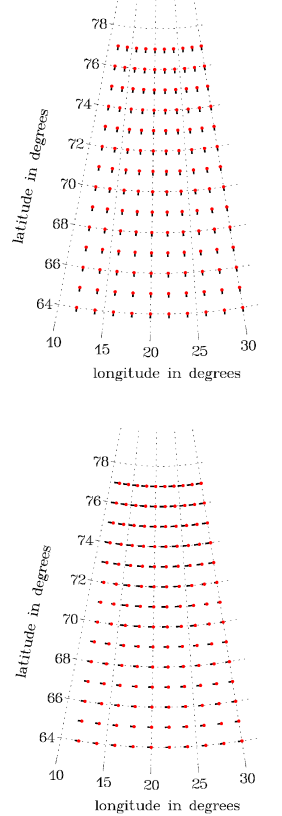

(2)

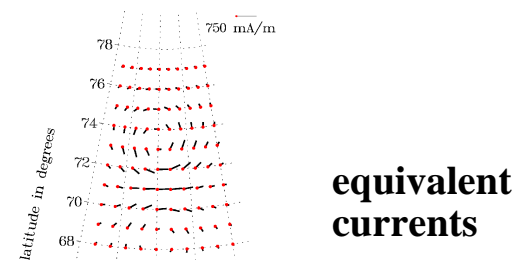

\section{electric}

currents

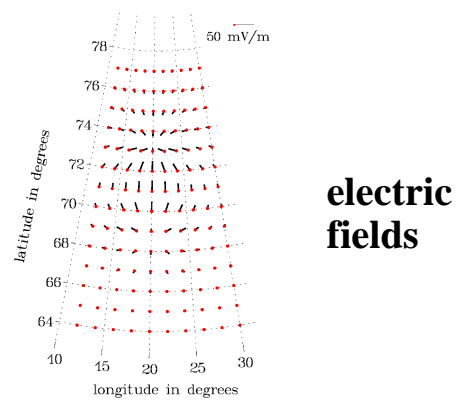

\section{Hall conductance}

\section{polarization field system}

$66+\cdots \cdots$

$\cdots+\cdots$

$\begin{array}{lllll}10 & 15 & 20 & 25 & 30\end{array}$
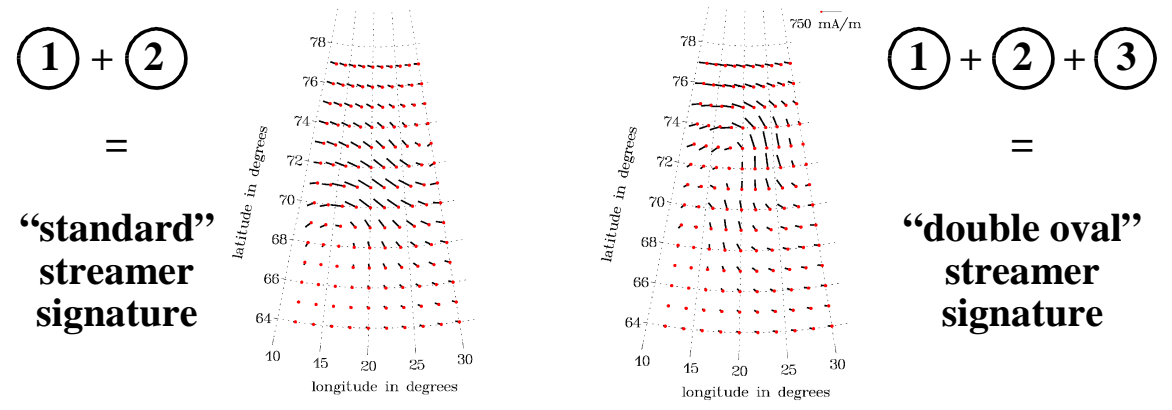

Fig. 12. Conceptual model of ionospheric electrodynamic features that contribute to the ionospheric equivalent currents signature of auroral streamers, containing three features: (1) streamer current wedge system; (2) background westward electrojet system; (3) polarization electric field system. The simplified electric field modeled for each system is shown in the second row, the modeled Hall conductance distribution in the first row, and the resulting ionospheric equivalent current distribution for each system is shown in the third row. Addition of (1) + (2) structurally reproduces the ionospheric equivalent current signature of "standard" streamers, while addition of (1) + (2) + (3) reproduces the one of "double oval" streamers like studied in this paper. 
the ionospheric equivalent current observations can be explained by the superposition of a few simple features of ionospheric electrodynamics.

The top row of Fig. 12 shows the Hall conductance distribution that has been adopted for our model. In the poleward portion of the double oval and in the region covered by the auroral streamer, a Hall conductance of $30 \mathrm{~S}$ is applied, and $20 \mathrm{~S}$ for the equatorward portion of the double oval. For the region in between the two ovals which is not covered by the streamer, a lower Hall conductance of $10 \mathrm{~S}$ is applied. A uniform Hall-to Pedersen conductance ratio of 1.5 is assumed. Note that for our conceptual model, here and in the following, the exact numbers are not of any major relevance, but they are chosen to roughly represent the basic structure that can be expected for an auroral streamer, based on the results of previous studies mentioned in the introduction.

For our model, we apply three basic electrodynamic features: (1) the current wedge associated with the auroral streamer, which is almost zonally aligned but slightly tilted into a northeast-southwestern direction, according to the results by, e.g., Amm et al. (1999) and Nakamura et al. (2005); (2) the background westward electrojet; and (3) the current system associated with the poleward pointing polarization electric field we have postulated above. The second row of Fig. 12 shows the modeled, simplified electric field structures of these three features: The electric field associated with the streamer wedge is modeled as a dipolar structure with the axis between the dipoles in northeast-southwestern direction and the positive pole in the northeast, the background westward electrojet is associated with an uniform southward electric field, and the polarization electric field is also modeled as a dipolar structure, with the axis between the dipoles aligned in meridional direction and the positive pole in the south. The third row of Fig. 12 then shows the resulting ionospheric equivalent currents for each of the three features, as calculated directly from the modeled distributions is rows 1 and 2, by using Ohm's law and calculating the magnetic field of each separate current system immediately below the ionosphere. Finally, in the fourth row of Fig. 12 we add together the total ionospheric equivalent currents from the constituents that are involved in the "standard" streamer (left-hand side) and the "double oval streamer" (right-hand side), respectively. The "standard streamer" consists of the streamer current wedge and the background westward electrojets (systems $1+2$ ), and indeed the sum of these two systems reproduces the standard equivalent current pattern typically found in association with an auroral streamer (cf., Amm et al., 1999; Nakamura et al., 2005; Juusola et al., 2009), namely a channel of enhanced equivalent currents flowing in northwestern direction and an anticlockwise vortical structure at the southwestern flank of this channel. On the other hand, when adding the ionospheric equivalent currents as produced by the suggested polarization electric field for the double oval situation on top of the standard streamer signature (systems $1+2+3$ ), we indeed arrive at a chan- nel of almost purely poleward directed equivalent currents, with fairly small equivalent currents eastward and westward of this channel, just as we observe it for our double oval streamer case.

Comparing the results of our simple, conceptual model for the double oval streamer case (Fig. 12, fourth row, right-hand side) with the observed ionospheric equivalent currents during the streamer event at 21:16 UT (Fig. 6, upper row, righthand side), we see that even though the magnitudes of the currents in the different parts do not exactly match (which was not the purpose of our conceptual model), the model is able to reproduce well the basic structure of the observed currents. Since different types of actual current systems may generate similar equivalent current systems, we emphasize that this is not a proof that our model represents the true ionospheric situation. However, our model shows that the suggested polarization electric field, which is also consistent with the EISCAT observations, is able to explain the difference between the standard and the double oval streamer signatures in terms of the ionospheric equivalent currents.

\section{Summary and conclusions}

We have presented and analyzed conjugate observations of a BBF in the magnetotail and an auroral streamer in the ionosphere on 14 September 2004, at $~ 21: 16$ UT, during the recovery phase of an auroral substorm. Data from the Cluster multi-satellite mission were used to identify the BBF and revealed a thick (in size) but thin (in density) plasma sheet during our event. Ionospheric observations of the auroral streamer associated with this BBF have been made by the MIRACLE network (in this study solely the IMAGE magnetometer stations which are part of this network were used) and the EISCAT radar located in northern Scandinavia, and the WIC instrument onboard the IMAGE satellite. This auroral streamer event happened in a "double oval" configuration of the ionosphere, with the recovery phase substorm auroral bulge being divided into a poleward and an equatorward oval that show significant auroral luminosity and currents flowing inside it, and a region in between those two portions of the oval with clearly diminished auroral luminosity and currents. The main results of our study can be summarized as follows:

1. In the Southern Hemisphere ionosphere conjugate to the $\mathrm{BBF}$, a clear signature of a mostly north-south aligned auroral streamer is seen during the BBF event.

2. In the Northern Hemisphere ionosphere conjugate to the $\mathrm{BBF}$, the spatial maps of ionospheric equivalent currents as generated from the MIRACLE data also show a clear signature during the BBF event, namely an intermittent channel of northward pointing equivalent currents in between the two portions of the double oval, with very small currents eastward and westward of this 
channel. This signature differs from the typical ionospheric equivalent current pattern of an auroral streamer without a double oval situation, as it has been observed in several previous studies, namely a channel of enhanced northwestward pointing currents with an anticlockwise vortical structure at its southwestern flank, and less sharp gradients of the magnitude of the currents at the flank of the channel.

3. Even though observed with different instruments, these clear and simultaneous signatures in the Northern and Southern Hemisphere ionosphere conjugate to the BBF indicate that for our event, an auroral streamer takes place simultaneously in the conjugate opposite hemispheres.

4. The total meridional equivalent ionospheric current transported by the recovery phase streamer in our event is $\sim 80 \mathrm{kA}$. This is much less than for previously analysed expansion phase streamers (e.g., $\sim 288 \mathrm{kA}$ for the event of Amm et al., 1999).

5. In order to explain the difference in the ionospheric equivalent current signature between our "double oval" streamer and the "standard" streamer signature observed in a number of previous events without a double oval situation, we propose that a poleward pointing polarization electric field is generated in the double oval situation, at the meridional boundaries between the oval portions and the less conductive region in between them. A conceptual model of the standard streamer and double oval streamer electrodynamics confirms that the current system associated with such a polarization electric field can indeed account for the observed structural difference in the ionospheric equivalent current signature. This model is also consistent with the observation by the EISCAT radar of an enhanced electric field structure associated with the streamer.

6. Both conclusions 4 and 5 above indicate that the development of auroral streamers is dependent on the prevailing background conditions of the ionospheremagnetosphere system.

Acknowledgements. The work of O.A. and K.K. was supported by the Academy of Finland (research projects 115947 and 132694). The work of C.J.O. was supported by the Science and Technology Facilities Council (STFC). EISCAT is an international scientific association supported by research organisations in China (CRIRP), Finland (SA), France (CNRS), Germany (DFG), Japan (NIPR and STEL), Norway (NFR), Sweden (VR), and the United Kingdom (NERC).

Guest Editor A. Masson thanks J. Vogt and another anonymous referee for their help in evaluating this paper.

\section{References}

Amm, O. and Kauristie, K.: Ionospheric signatures of bursty bulk flows, Surv. Geophys., 23, 1-32, 2002.

Amm, O. and Viljanen, A.: Ionospheric disturbance magnetic field continuation from the ground to the ionosphere using spherical elementary current systems, Earth, Planets Space, 51, 431-440, 1999.

Amm, O., Pajunpää, A., and Brandström, U.: Spatial distribution of conductances and currents associated with a north-south auroral form during a multiple-substorm period, Ann. Geophys., 17, 1385-1396, doi:10.1007/s00585-999-1385-6, 1999.

Amm, O., Engebretson, M. J., Hughes, T., Newitt, L., Viljanen, A., and Watermann, J.: A traveling convection vortex event study: Instantaneous equivalent currents, estimation of fieldaligned currents, and the role of induced currents, J. Geophys. Res., 107(A11), 1334, doi:10.1029/2002JA009472, 2002.

Angelopoulos, V., Baumjohann, W., Kennel, C. F., Coroniti, F. V., Kivelson, M. G., Pellat, R., Walker, R. J., Lühr, H., and Paschmann, G.: Bursty bulk flows in the inner central plasma sheet, J. Geophys. Res., 97, 4027-4039, 1992.

Angelopoulos, V., Kennel, C. F., Coroniti, F. V., Pellat, R., Kivelson, M. G., Walker, R. J., Russell, C. T., Baumjohann, W., Feldman, W. C., and.Gosling, J. T.: Statistical characteristics of bursty bulk flow events, J. Geophys. Res., 99, 21257-21280, 1994.

Balogh, A., Carr, C. M., Acuña, M. H., Dunlop, M. W., Beek, T. J., Brown, P., Fornacon, K.-H., Georgescu, E., Glassmeier, K.H., Harris, J., Musmann, G., Oddy, T., and Schwingenschuh, K.: The Cluster Magnetic Field Investigation: overview of in-flight performance and initial results, Ann. Geophys., 19, 1207-1217, doi:10.5194/angeo-19-1207-2001, 2001.

Baumjohann, W., Paschmann, G., and Lühr, H.: Characteristics of high-speed ion flows in the plasma sheet, J. Geophys. Res., 95, 3801-3809, 1990.

Chen, C. X. and Wolf, R. A.: Interpretation of high-speed flows in the plasma sheet, J. Geophys. Res., 98, 21409-21419, 1993.

Chen, C. X. and Wolf, R. A.: Theory of thin-filament motion in Earth's magnetotail and its application to bursty bulk flows, J. Geophys. Res., 104, 14613-14626, 1999.

Dunlop, M. W., Balogh, A., Glassmeier, K.-H., and Robert, P.: Four-point Cluster application of magnetic field analysis tools: The Curlometer, J. Geophys. Res., 107(A11), 1384, doi:10.1029/2001JA005088, 2002.

Elphinstone, R. D., Murphree, J. S., Hearn, D. J., Cogger, L. L., Sandahl, I., Newell, P. T., Klumpar, D. M., Ohtani, S., Sauvaud, J. A., and Potemra, T. A.: The double oval UV auroral distribution. 1: Implications for the mapping of auroral arcs, J. Geophys. Res., 100, 12075-12092, 1995.

Escoubet, C. P., Fehringer, M., and Goldstein, M.: Introduction: The Cluster mission, Ann. Geophys., 19, 1197-1200, doi:10.5194/angeo-19-1197-2001, 2001.

Folkestad, K., Hagfors, T., and Westerlund, S.: EISCAT: An updated description of technical characteristics, Radio Sci., 18, 867-879, 1983.

Forsyth, C., Lester, M., Cowley, S. W. H., Dandouras, I., Fazakerley, A. N., Fear, R. C., Frey, H. U., Grocott, A., Kadokura, A., Lucek, E., Rème, H., Milan, S. E., and Watermann, J.: Observed tail current systems associated with bursty bulk flows and auroral streamers during a period of multiple substorms, Ann. Geophys., 
26, 167-184, doi:10.5194/angeo-26-167-2008, 2008.

Gjerloev, J. W., Hoffman, R. A., Sigwarth, J. B., Frank, L. A., and Baker, J. B. H.: Typical auroral substorm: A bifurcated oval, J. Geophys. Res., 113, A03211, doi:10.1029/2007JA012431, 2008.

Henderson, M. G., Reeves, G. D., and Murphree, J. S.: Are northsouth aligned auroral structures an ionospheric manifestation of bursty bulk flows?, Geophys. Res. Lett., 25, 3737-3740, 1998.

Juusola, L., Nakamura, R., Amm, O., and Kauristie, K.: Conjugate ionospheric equivalent currents during bursty bulk flows, J. Geophys. Res., 114, A04313, doi:10.1029/2008JA013908, 2009.

Kauristie, K., Sergeev, V. A., Kubyshkina, M., Pulkkinen, T. I., Angelopoulos, V., Phan, T., Lin, R. P., and Slavin, J. A.: Ionospheric current signatures of transient plasma sheet flows, J. Geophys. Res., 105, 10677-10690, 2000.

Kubyshkina, M. V., Sergeev, V. A., and Pulkkinen, T. I.: Hybrid Input Algorithm: An event-oriented magnetospheric model, J. Geophys. Res., 104, 24977-24993, 1999.

Mende, S. B., Heetderks, H., Frey, H. U., Lampton, M., Geller, S. P., Abiad, R., Siegmund, O., Tremsin, A. S., Spann, J., Dougani, H., Fuselier, S. A., Magoncelli, A. L., Bumala, M. B., Murphree, S., and Trondsen, T.: Far ultraviolet imaging from the IMAGE spacecraft: 2. Wideband FUV imaging, Space Sci. Rev., 91, 271285, 2000.

Nakamura, R., Baumjohann, W., Schödel, R., Brittnacher, M., Sergeev, V. A., Kubyshkina, M., Mukai, T., and Liou, K.: Earthward flow bursts, auroral streamers, and small expansions, J. Geophys. Res., 106, 10791-10802, 2001.

Nakamura, R., Baumjohann, W., Klecker, B., Bogdanova, Y., Balogh, A., Rème, H., Bosqued, J. M., Dandouras, I., Sauvaud, J. A., Glassmeier, K.-H., Kistler, L., Mouikis, C., Zhang, T. L., Eichelberger, H., and Runov, A.: Motion of the dipolarization front during a flow burst event observed by Cluster, Geophys. Res. Lett., 29(20), 1942, doi:10.1029/2002GL015763, 2002.

Nakamura, R., Baumjohann, W., Mouikis, C., Kistler, L. M., Runov, A., Volwerk, M., Asano, Y., Voeroes, Z., Zhang, T. L., Klecker, B., Reme, H., and Balogh, A.: Spatial scale of high-speed flows in the plasma sheet observed by Cluster, Geophys. Res. Lett., 31, L09804, doi:10.1029/2004GL019558, 2004.

Nakamura, R., Amm, O., Laakso, H., Draper, N. C., Lester, M., Grocott, A., Klecker, B., McCrea, I. W., Balogh, A., Rème, H., and André, M.: Localized fast flow disturbance observed in the plasma sheet and in the ionosphere, Ann. Geophys., 23, 553-566, doi:10.5194/angeo-23-553-2005, 2005.

Pitkänen, T., Aikio, A. T., Amm, O., Kauristie, K., Nilsson, H., and Kaila, K. U.: EISCAT-Cluster observations of quiet-time near-Earth magnetotail fast flows and their signatures in the ionosphere, Ann. Geophys., 29, 299-319, doi:10.5194/angeo29-299-2011, 2011.

Pontius Jr., D. H. and Wolf, R. A.: Transient flux tubes in the terrestrial magnetosphere, Geophys. Res. Lett., 17, 49-52, 1990.

Rème, H., Aoustin, C., Bosqued, J. M., Dandouras, I., Lavraud, B., Sauvaud, J. A., Barthe, A., Bouyssou, J., Camus, Th., CoeurJoly, O., Cros, A., Cuvilo, J., Ducay, F., Garbarowitz, Y., Medale, J. L., Penou, E., Perrier, H., Romefort, D., Rouzaud, J., Vallat, C., Alcaydé, D., Jacquey, C., Mazelle, C., d'Uston, C., Möbius, E., Kistler, L. M., Crocker, K., Granoff, M., Mouikis, C., Popecki, M., Vosbury, M., Klecker, B., Hovestadt, D., Kucharek, H., Kuenneth, E., Paschmann, G., Scholer, M., Sckopke, N., Seidenschwang, E., Carlson, C. W., Curtis, D. W., Ingraham, C., Lin, R.
P., McFadden, J. P., Parks, G. K., Phan, T., Formisano, V., Amata, E., Bavassano-Cattaneo, M. B., Baldetti, P., Bruno, R., Chionchio, G., Di Lellis, A., Marcucci, M. F., Pallocchia, G., Korth, A., Daly, P. W., Graeve, B., Rosenbauer, H., Vasyliunas, V., McCarthy, M., Wilber, M., Eliasson, L., Lundin, R., Olsen, S., Shelley, E. G., Fuselier, S., Ghielmetti, A. G., Lennartsson, W., Escoubet, C. P., Balsiger, H., Friedel, R., Cao, J.-B., Kovrazhkin, R. A., Papamastorakis, I., Pellat, R., Scudder, J., and Sonnerup, B.: First multispacecraft ion measurements in and near the Earth's magnetosphere with the identical Cluster ion spectrometry (CIS) experiment, Ann. Geophys., 19, 1303-1354, doi:10.5194/angeo19-1303-2001, 2001.

Schödel, R., Baumjohann, W., Nakamura, R., Sergeev, V. A., and Mukai, T.: Rapid flux transport in the central plasma sheet, J. Geophys. Res., 106, 301-313, doi:10.1029/2000JA900139, 2001.

Sergeev, V. A., Angelopoulos, V., Gosling, J. T., Cattell, C. A., and Russell, C. T.: Detection of localized, plasma-depleted flux tubes or bubbles in the midtail plasma sheet, J. Geophys. Res., 101, 10817-10826, 1996.

Sergeev, V. A., Sauvaud, J.-A., Popescu, D., Kovrazhkin, R. A., Liou, K., Newell, P. T., Brittnacher, M., Parks, G., Nakamura, R., Mukai, T., and Reeves, G. D.: Multiple-spacecraft observation of a narrow transient plasma jet in the Earth's plasma sheet, Geophys. Res. Lett., 27(6), 851-854, doi:10.1029/1999GL010729, 2000.

Sergeev, V. A., Liou, K., Newell, P. T., Ohtani, S.-I., Hairston, M. R., and Rich, F.: Auroral streamers: characteristics of associated precipitation,convection and field-aligned currents, Ann. Geophys., 22, 537-548, doi:10.5194/angeo-22-537-2004, 2004.

Snekvik, K., Haaland, S., Østgaard, N., Hasegawa, H., Nakamura, R., Takada, T., Juusola, L., Amm, O., Pitout, F., Rème, H., Klecker, B., and Lucek, E. A.: Cluster observations of a field aligned current at the dawn flank of a bursty bulk flow, Ann. Geophys., 25, 1405-1415, doi:10.5194/angeo-25-1405-2007, 2007.

Takada, T., Nakamura, R., Juusola, L., Amm, O., Baumjohann, W., Volwerk, M., Matsuoka, A., Klecker, B., Snekvik, K., Owen, C. J., Fazakerley, A. N., Frey, H. U., Rème, H., Lucek, E. A., and Carr, C.: Local field-aligned currents in the magnetotail and ionosphere as observed by a Cluster, Double Star, and MIRACLE conjunction, J. Geophys. Res., 113, A07S20, doi:10.1029/2007JA012759, 2008.

Tsyganenko, N. A.: A magnetospheric field model with a warped tail current sheet, Planet. Space Sci., 37, 5-20, 1989.

Untiedt, J. and Baumjohann, W.: Studies of polar current systems using the IMS Scandinavian magnetometer array, Space Sci. Rev., 63, 243-390, 1993.

Vanhamäki, H., Amm, O., and Viljanen, A.: 1-dimensional upward continuation of the ground magnetic field disturbance using spherical elementary current systems, Earth Planets Space, 55, 613-625, 2003.

Viljanen, A. and Häkkinen, L.: IMAGE magnetometer network, in: Satellite-Ground Based Coordination Sourcebook, edited by: Lockwood, M., Wild, M. N., and Opgenoorth, H. J., ESA publications SP-1198, pp. 111, 1997. 